\title{
The Application of Salutogenesis in Primary Care
}

\author{
Daniela Rojatz, Peter Nowak, Ottomar Bahrs, \\ and Jürgen M. Pelikan
}

\section{Introduction}

Behind the terms 'primary care' and 'salutogenesis' are visions, values, and structures. Primary care, understood as the first contact point to medical care, operates at the interface between the social and health systems, the patient with his or her family and professional environment, and the local population. Primary (health) care is envisioned to contribute to universal health coverage and equality. Salutogenesis describes an orientation towards health, a model, and the construct 'sense of coherence'. This chapter is dedicated to the application of salutogenesis in primary care.

Primary care services are a complex of strongly interrelated professional practice, research, and supporting policy. Therefore, applying salutogenesis in primary care comprehensively should include introducing salutogenesis in all these fields simultaneously (Pelikan, 2017).

This chapter examines how salutogenesis is addressed and discussed in policy, research, and practice. Moreover, it discusses the application of salutogenesis as a health orientation, a model, and a construct 'sense of coherence" in primary care. In doing so, we contribute to applying salutogenesis in primary care and provide an outlook on further research needs.

In the first step, we try to make comprehensible what characterizes primary care, salutogenesis, and finally, the meaningfulness of salutogenic primary care. Subsequently,

D. Rojatz $(\varangle) \cdot$ P. Nowak

Austrian National Public Health Institute (Gesundheit Österreich

$\mathrm{GmbH})$, Vienna, Austria

e-mail: daniela.rojatz@goeg.at

O. Bahrs

University of Düsseldorf, Düsseldorf, Germany

Umbrella Organization Salutogenesis, Göttingen, Germany

e-mail: obahrs@dachverband-salutogenese.de

J. M. Pelikan

University of Vienna, Vienna, Austria

WHO-Collaborating Centre for Health Promotion in Hospitals and Healthcare at the Austrian National Public Health Institute

(Gesundheit Österreich GmbH), Vienna, Austria the chapter examines how salutogenesis is addressed and 'managed' in policy, research, and practice. Moreover, it discusses the application of salutogenesis as a health orientation, model, and sense of coherence in primary care.

\section{Defining Key Terms: Primary Care and Salutogenesis}

Since the terms primary care and salutogenesis are quite broad, it is important to show their variety and give orientation on how both terms are subsequently understood and highlight the importance of applying salutogenesis in primary care.

\section{Primary Care}

The terms 'primary care' and 'primary health care' are sometimes used interchangeably. We follow the WHO definition and differentiate between primary health care and primary care (Muldoon et al., 2006; WHO, 2018a).

Primary health care (PHC), according to the World Health Organization (WHO), is defined as '[a] whole-of-society approach to health that aims to maximize the level and distribution of health and well-being through three components:

(a) Primary care and essential public health functions as the core of integrated health services;

(b) Multisectoral policy and action; and,

(c) Empowering people and communities' (WHO and UNICEF, 2018, p. 40).

These three elements indicate that primary health care ideally resonates with people' and community needs through integrated health care and policy.

In contrast, primary care is a subset of PHC. It refers to '[a] key process in the health system that supports firstcontact, accessible, continuous, comprehensive, and 
coordinated patient-focused care' (WHO and UNICEF, 2018 , p. 40). There is no commonly used definition of primary care, but most definitions share the following attributes which are used to assess primary care (Muldoon et al., 2006; Starfield et al., 2005):

- First contact care can have two meanings: the first contact with the care system or the basic service level of health care.

- Accessibility: to provide service as close as possible to where people live and work.

- Comprehensiveness: to address any health problem at any given stage of a patient's life cycle.

- Coordination of care: to ensure the coordination of services and information a patient needs.

- Continuity: to care in long-standing relationships.

These aspects are also mirrored in the definitions of 'family medicine' and 'general physician' 'of the World Organization of Family Doctors (WONCA) (Jamoulle et al., 2017). In this context, it is important to mention that most minor health issues are solved by sick individuals and their social network as self-care (Sprenger, 2012). Therefore, households are the first and most important level of care and health promotion (Bhuyan, 2004; Pandey, 2018). Primary care services are in a unique position to accompany households and individuals if they cannot manage ill-health by themselves. Thus, the co-production of health through cooperation between health professionals and patients (including shared decision making) (Elwyn et al., 2012) is an essential part of primary care. The coproduction of health care is defined as 'the interdependent work of users and professionals to design, create, develop, deliver, assess and improve the relationships and actions that contribute to the health of individuals and populations' (Batalden et al., 2016). Thus, on a micro-level, the basic primary care units are the co-productions based on the relationships and communications between single patients and their physicians (health professionals) (Hart, 1998; Rudebeck, 2019). Therefore, primary care is located at the interface of community and health care and social and medical services.

Comparative research on primary care (e.g. on its structure, process and outcomes) in Europe is quite limited (Kringos et al., 2015). Primary care structure and strength vary greatly, not only among European countries (Kringos et al., 2015). The primary care professions differ from health system to health system and may include general practitioners, pharmacists, general paediatrics, gynaecologists and gerontologists. In some countries, advanced nurse practitioners play a major role in primary care; in other countries, the structure is more physician-centred.

\section{Salutogenesis as an Orientation, a Model, and the Sense of Coherence}

'What keeps people healthy?' is the central question Aaron Antonovsky asked. This question introduces a shift from pathogenesis (an orientation on deficits and diseases) to salutogenesis (an orientation towards positive health and health resources).

Antonovsky considers salutogenesis as a conceptual foundation of health promotion (Antonovsky, 1996). Health promotion has been defined as 'the process of enabling people to increase control over and improve their health' (WHO, 1986, p. 1). In practice, health can be regarded as the ability to cope with stressors/challenges of life and to live a meaningful life. In other words, health means that a person is in resonance (resonates) with himself/herself, its immediate environment/life areas, and the wider world (Rosa, 2016). But health is not only a matter of an individual. Fundamental requirements for or determinants of health are situational factors like peace, shelter, and education (Dahlgren \& Whitehead, 2007). Therefore, the realization of health (promotion) needs an interplay of all sectors of society (WHO, 1986).

Also, each person has his/her subjective ideas of health and well-being (Blättner \& Waller, 2011), which among other things, derive from cultural and biographical experiences and overarching life goals (Matthiessen, 2010). This applies to all people in the context of primary care - patients, health professionals, and the local community (Kreher et al., 2008; Watson, 2008) and is therefore important to be considered in interactions in primary care and for the implementation of salutogenesis.

An important determinant for health - especially concerning healthcare settings - is health literacy. Health literacy is a relational concept defined as finding, understanding, appraising, and applying health-related information. The ability depends on health-literate patients and health-literate healthcare organizations (i.e. how easy it is to find your orientation in the organization) (Parker, 2009).

In contrast to health promotion, disease prevention is oriented towards illness or health risks and aims to prevent or mitigate these. In practice, disease prevention and health promotion are often overlapping. Their differentiation depends on the intention behind a measure (e.g. a healthy diet can promote health or prevent illnesses).

Although health promotion mostly builds just on a vague, general salutogenic orientation (Bauer et al., 2019), the paradigm of salutogenesis offers more specific concepts and instruments for guiding health promotion interventions and reorienting services towards health. Three quite different conceptual forms of using salutogenesis can be distinguished (Pelikan, 2017): 
1. The salutogenic orientation: Human existence is inherently flawed, and therefore coping with tensions is universal and not exceptional (Antonovsky, 1996). There exists a health-dis-ease continuum and not a dichotomy of either healthy or sick people. A salutogenic orientation in health care means to consider the health of all persons involved (patients, relatives, staff and local community) and all aspects of their health (not only disease-specific ones) and focus on salutary and not just risk factors. This holistic perspective corresponds well with holistic treatment approaches in primary care for patients. It is further expanded by the settings approach of health promotion in health care to include staff and the region's population.

2. The salutogenic model is somewhat complicated and has hardly been taken up by Antonovsky or other authors (Pelikan, 2017). Within this model, the concept of generalized resistance resources (GRRs) is introduced as 'a property of a person, a collective or a situation which, as evidence or logic has indicated, facilitated successful coping with the inherent stressors of human existence' (Antonovsky, 1996, p. 15). The application of GRRs to primary care seems promising as it recognizes existing resources and competencies of human beings (patients and their families), staff, and community. It affords a more holistic and complex perspective and a widening of diagnostic and therapeutic methods applied (Pelikan, 2017). Current challenges in primary care (e.g. little interest in becoming a general practitioner, lack of communication time, and financial investment) can be understood as an imbalance between resistance resources and stressors for primary care settings.

3. The construct of sense of coherence (SOC) is a core element of the salutogenic model. Of the three concepts, it is the one most used in research. SOC is defined as the experienced comprehensibility, manageability, and meaningfulness of a situation. Therefore, SOC can be interpreted as a moderator, a mediator of other determinants of health or outcome measure (Pelikan, 2017). SOC is also defined by Antonovsky (1979) as 'confidence' in a predictable environment or the view of life being meaningful (Antonovsky, 1996). To be healthy can be regarded as being in a fulfilling, happy resonance with a specific situation, person, or other aspects of life (Bauer et al., 2019).

In sum, salutogenesis for primary care means to:

- Consider all people involved: patients, relatives, staff, and the community served.

- Take the current position of the person on the ease/dis-ease continuum into account.

- Focus on resources and risk factors in dealing with a situation (e.g. illness).

- Search for comprehensive, meaningful, and manageable interventions for patients, increasing their confidence in coping with their illness and life, and taking respective measures for staff and the local community.

Conversely, key assets of primary care for salutogenesis are the frequent, continuous, and trustworthy relationships between health professionals (general practitioners and their teams) and patients (and their families) as well as the holistic approach of primary care.

\section{Salutogenesis and Its Relevance to Primary Care}

Salutogenic primary care refers to salutogenesis as orientation, model, and SOC.

Derived from considerations in health promotion, one can differentiate between 'health-promoting practice' (a salutogenic orientation of primary care organization and its core processes) and 'health promotion in practice' (single salutogenic measures as an add-on in primary care). The add-on approach seems to dominate in primary care practice, whereas a fundamental salutogenic orientation of the core processes is still rare (Bahrs \& Matthiessen, 2007; Boyce et al., 2010; Klein et al., 2017; Peckham et al., 2017).

Ideally, salutogenic primary care has integrated a salutogenic orientation in its core processes. It develops a healthpromoting/salutogenic setting that focuses on the comprehensive/holistic health of staff (health professionals), patients, relatives, and the local community (Watson, 2008). Salutary factors should be considered along with risk factors within curative, preventive, protecting, and promoting practices and relevant aspects of local communities and settings.

The salutogenic model could be a resource to understand and use the interplay of diverse resources of patients, staff, and communities to better cope with health risks and stressors in salutogenic primary care. One of the primary resources in this context is health literacy: 'salutogenesis can be conceived as a constant learning process supporting the movement towards health (and other desired aspects of one's existence) via improving health literacy' (Erikson, 2017, p. 92). Although the relationship between health literacy and salutogenesis needs more theoretical reflection and much more research (Jensen et al., 2017), Bauer et al. (2019) recommend the promotion of health literacy to create competent citizens able to take control over their health and as a goal for chronic disease management (Pelikan, 2017). Studies of health literacy demonstrate that comprehension of healthcare tasks is difficult for many patients (Sørensen et al., 2015). Furthermore, it is argued that healthcare staff have to improve their health literacy to support the comprehensibility, manageability, and meaningfulness of health care (SOC) for their patients (Dietscher et al., 2017).

Health literate health care was developed explicitly in the context of 'health-promoting hospitals' initiatives, and salu- 
togenesis and the SOC are seen as a specific dimension of quality of healthcare organizations (Dietscher et al., 2017). For example, the development of salutogenic 'standards' (Dalton \& Mccartney, 2011) is recommended to make institutional contexts more salutogenic. These insights can be transferred to some extent to the primary care setting - as shown by the Austrian case below - but health literate and salutogenic primary care have specific opportunities as the first contact with care. When they have health concerns, primary care may be the only resource available to vulnerable groups and individuals with low health literacy. Health literate primary care relates especially to the challenging navigation within the healthcare system - making the healthcare system better understandable, accessible, and meaningful. Salutogenic primary care can increase the understanding of health, health promotion, disease prevention, and self-care of minor illnesses in the context of everyday life, thus empowering people for self-management.

Summing up, salutogenic primary care can be envisioned as care that is comprehensible, manageable, and meaningful for patients, residents, and the staff. Salutogenic primary care is oriented towards positive health integrated into its core processes and adapted to its patients' needs. It aims in a person-centred manner at enabling or empowering the helpseeking person/user to improve her/his health in everyday life, especially by health literacy measures and by developing a health literate organization. The primary care team's health resources and needs are also perceived as essential for salutogenic primary care. Staff should be enabled for interdisciplinary work that allows for a holistic perception and treatment of patients. From a public health perspective, this also includes going beyond the person by addressing the local community's health and taking other relevant social and medical services into account. Therefore, salutogenic primary care is in resonance with the social and medical system and individuals including their social network.

\section{Salutogenesis and Primary Care in Policy, Research and Practice}

How far is the application of salutogenesis in primary care taken up in policy, research, and practice?

\section{Policy: Approaching Salutogenic Primary Care by Relating it to Public Health and Health Promotion}

In this section, we use documents of the WHO as a proxy for the policy discussion on salutogenic/health-oriented primary care. WHO has been advocating for health-promoting services in primary care since the Alma Ata declaration more than 40 years ago: Primary care 'addresses the main health problems in the community, providing promotive, preventive, curative, and rehabilitative services accordingly' (WHO, 1978). The Ottawa-Charta (WHO, 1986) reinforced this by explicitly calling for a reorientation of health services by moving 'increasingly in a health promotion direction beyond its responsibility for providing clinical and curative services'. By a change in their perspective and organization, health services should focus on the individual's needs as a whole person. Realizing reorientation requires shared efforts from health services, community groups, health professionals, and individuals (WHO, 1986).

More recently, the WHO emphasized health-promoting and therefore implicitly salutogenic - primary care by the Astana-Declaration and integrating public health and primary (health) care (WHO, 2018a). Public health is defined as 'the art and science of preventing disease, prolonging life, and promoting health through society's organized efforts' (Acheson, 1988). Integrating public health into primary care emphasizes a shift from the individual patient to a populationoriented perspective. WHO defined 10 essential Public Health Operations (WHO Europe, 2012). Three of these, concerning service delivery, are health promotion, disease prevention, and health protection. Health care and public health services need to be linked to reaching their potentials (Kringos et al., 2015). A recent publication summarizes models to link primary health care and public health services (WHO, 2018b). This opens a window for the application of salutogenesis and health promotion in primary care, including a patient-centred approach and community orientation.

Moreover, primary health care can play a central role in meeting sustainable development goals (SDGs) adopted by the United Nations in 2015 (Pettigrew et al., 2015). From the perspective of salutogenesis, working to achieve the UN Sustainable Development Goals (SDGs) strengthens general resistance resources. Primary care is key to meet goal 3 'Ensure healthy lives and promote well-being for all at all ages', in particular, by target 3.4.: 'reduce by one-third premature mortality from non-communicable diseases through prevention and treatment and promote mental health and well-being'. The SDGs also underline the aim of Universal Health Coverage (UHC) (WHO, 2019). UHC means that all people have access to health services, including health promotion, when and where they need services, without incurring financial hardship (WHO and UNICEF, 2018). Especially this request for also having access to health promotion underlines the importance of salutogenic primary care.

In sum, primary care is discussed in the policy discourse as important for health promotion and public health but without explicit reference to salutogenesis. Health-oriented primary care is seen as relevant to meet the SDGs, realize UHC, and save costs and be a general resistance resource for society. 


\section{Research: Application of Salutogenesis in Primary Care}

We conducted a literature review to summarize the peerreviewed literature on 'salutogenesis and primary care' in spring 2020. Using a Scopus search resulted in only 118 citations for salutogenesis (but over 18.000 results for health promotion). In an abstract review, we excluded 67 articles due to not focusing on primary care. The included studies originated mainly from Europe (primarily Sweden and Denmark). They addressed primary care mainly in general (i.e. without describing the specific setting) as general practices or primary care centres. Just a few studies referred to other facilities like dentists (Hjalmers et al., 2004). Target groups of the studies are mainly patients, subsequently primary care staff. We summarize the literature following the three constructs of salutogenesis (orientation, model and SOC).

\section{Salutogenesis as an Orientation}

Some studies report on considerations to reorient primary care towards positive health. For example, Hollnagel and Malterud (1995) present a clinical model to shift the attention from objective risk factors to patients' self-assessed health resources. Braun (2004) highlights a resource-oriented approach as a measure to overcome increasing doctor and patient discontent. Kröger and Altmeyer (2013) highlight the need to reorient primary care towards health. Some others used salutogenesis to illuminate the holistic nature of primary care practice (e.g. nurses) (Grant et al., 2017; SangsterGormley et al., 2013).

\section{Salutogenesis as a Model}

The few studies, which used the salutogenesis model as a conceptual basis, did this on an interactive micro level, for example, in the development of salutogenic (resourceoriented) language (Malterud \& Hollnagel, 1997, 1998), of salutogenic dialogue with patients or salutogenic sessions. Interventions such as salutogenic dialogue try to create supportive space and time for patients and health professionals to interact in practice (Rakel, 2008) or preventive visits (Lagerin et al., 2016).

\section{SOC as an Outcome Measure}

Most studies refer to single intervention studies using the SOC as an outcome measure. Studies showed, for example, that frequent attenders of primary care in Sweden have a lower SOC than the control group (Bergh et al., 2006;
Rennemark et al., 2009). There is also some evidence that specific health-oriented interventions in primary care lead to significant changes in SOC: In their randomized control trial, Arvidsdotter et al. (2015) compared therapeutic acupuncture, salutogenic dialogue, and conventional treatment concerning psychological distress. They found that acupuncture and salutogenic dialogue improve the patients' SOC and mental health status, whereas conventional therapy was less beneficial. Heggdal and Lovaas (2018) investigated changes in an individual's SOC when engaging in health promotion interventions and found significant changes in SOC, especially concerning community resources.

A few studies dealt with the resources of general practitioners or nurses (e.g. SOC, supervision, health-promoting leadership, and salutogenic work-related factors) in recognizing their health as the basis for providing services to others (Ejlertsson et al., 2018; Mazur et al., 2018; Palsson et al., 1994; Siber et al., 2009).

\section{Practice: Piloting the Application of Health Promotion and Salutogenesis in Primary Care}

Subsequently, two pilot projects are introduced, which exemplify diverse approaches to salutogenic primary care. The first introduces the concept of review dialogue, facilitating a salutogenic interaction between patients and health professionals. The second pilot project describes a path to systematically implement health promotion, health literacy, and disease prevention in new multi-professional primary care units.

\section{Application of Salutogenesis in Primary Care Practice: Review Dialogue}

The concept of review dialogue was developed in the framework of a study sponsored by the German AOK Federal Association (2002-2006) to analyse conditions that promote and hinder GP's health-oriented practice (Bahrs et al., 2004; Bahrs \& Matthiessen, 2007). According to its selfunderstanding, family medicine as a specific aspect of primary care is characterized, among other things, by having a health education function and eliciting and promoting health resources as part of GPs' daily practice (DEGAM, 2012; Sturm et al., 2006). It was assumed that active listening as a core element of the GP's conversation could strengthen the patient's SOC concerning all dimensions mentioned by Antonovsky:

- The feeling of meaningfulness (a) by experience being taken seriously and accepted as a unique person and (b) 
by experience in which dealing with health and illness, is considered valuable.

- The feeling of comprehensibility by (a) taking up the patient's illness theory, (b) the provision of information about possible causes and the course of the illness as well as the reflection on what the formation of symptoms may have been good for.

- The feeling of manageability by (a) shared perception of (existing or accessible) resources and (b) the certainty that the general practitioner and her professional help system are available as support.

To be able to take into account already existing competencies ('resource orientation') and the diversity of perspectives in dealing with chronic illness, two regional interdisciplinary quality circles (QC) were initiated during the project, and patients were continuously involved in the discussions (Bahrs \& Andres, 2016). The discussion of experiences in these QC made clear that the patients' lifeworld and the therapists' professional orientation did not fit. The treatment of 'target diseases' (diabetes or chronic respiratory diseases) was often not a priority from the patient's perspective. The developed routines and ritualized procedures in primary care practice left little room for clarification between GP and patients. A new conversation format was developed and tested to interrupt the frustrating pattern for patients and physicians: the review dialogue (RD).

In an $\mathrm{RD}$, the physician invites his patient to a 30-minute conversation to work out the patient's central problems holistically, recognize previous solutions, mutually agree on priorities, formulate health goals jointly, and develop ways to achieve these goals. The RD was systematically discussed in the $\mathrm{QC}$, and a new patient-centred process structure (Bahrs, 2011) was developed, which was evaluated on a case-bycase basis, across all cases, supplementary patient surveys as well as by a clustered-randomized study. Results show an improved relationship, more tailored treatment, empowerment, greater satisfaction of patients and practitioners (Bahrs et al., 2017; Bahrs \& Matthiessen, 2007; Kaschel, 2018). Most patients and physicians wanted the RDs to be continued; some physicians already integrate the RD into their daily routine ('RD hours'). The implementation of the concept varied considerably ('physician factor'). Younger female doctors with prior qualifications in psychosocial medicine (or complementary medicine) tended more towards salutogenic conversations. The central role of relationship formation was demonstrable in every case study: health development is an interactive process that professionals can support simultaneously through task-related and relationship work (Bahrs \& Henze, 2019).

However, doctors and patients first had to learn their new roles. Uncertainties and adaptation problems accompanied the change. Accompanying QC can provide support here
(Bahrs \& Matthiessen, 2007). Case-related work in the QC makes it possible to:

- Develop tailor-made interventions.

- Promote an exemplary hermeneutic understanding of cases and a salutogenic orientation through a multiperspective view.

- Track progress.

- Support the transfer of knowledge from practice to develop theories and interventions (Bahrs \& Andres, 2016).

QC as a means/method of participatory research and continuous quality improvement can contribute to professional development towards acting more salutogenic by the professionals (Bahrs \& Andres, 2016).

According to available experience, the RD has changed from a promising intervention to a proven intervention and has found its way into various guidelines (DEGAM, 2017; DEGAM-Praxisempfehlung, 2016).

\section{Applying Health Orientation and Salutogenesis to Primary Care: Piloting a Comprehensive Approach}

The Austrian healthcare reform aims to strengthen primary care. A new primary care concept was developed and adopted (Bundesministerium für Gesundheit, 2014). Salutogenesis is not explicitly mentioned in there. However, health promotion, health literacy, and prevention are highlighted as key elements of the new primary care units and as a key competence of the new multidisciplinary primary care teams (e.g. GPs, nurses, social workers, psychologists, midwives, physiotherapists, etc.) (BMGF, 2018; Bundesministerium für Gesundheit, 2014). New is also that the units must serve the local community (not only patients coming to the facility).

However, in this policy document, health promotion, health literacy, and disease prevention were hardly defined. That's where the project funded by the Main Association of Austrian Social Security Institutions and the Funds for a Healthy Austria came in. Based on an initial study (Klein et al., 2017), it uses a systematic approach that integrates health promotion, disease prevention, and health literacy to establish health-oriented primary care and increase SOC and comprehensive health gain for patients, staff, and the community. Health gain can be achieved through disease prevention (the avoidance of risks) and health promotion (the strengthening of health resources). Measures to strengthen health literacy, such as good communication, target grouporiented and evidence-based health information and a health literate primary care unit support measures of prevention and health promotion. Based on a better understanding and man- 
ageability of these concepts, the project intends to further a salutogenic orientation for the health system, staff, and patients/population.

Since systematic change requires multi-strategic implementation addressing multiple domains (Harnett, 2018), the project simultaneously addresses the macro-, meso- and micro-levels of health care.

\section{Macro-level}

On the macro-level, the project tries to strengthen the meaningfulness of health-oriented primary care (i.e. health promotion, disease prevention, and health literacy as integrated tasks of primary care units) by discussing the basic concepts and practical application of health-oriented processes and practices with primary care staff and the relevant stakeholders of Austria's health administration. To make health promotion, health literacy, and disease prevention manageable for primary care units, key prerequisites for implementing health-oriented primary health care (e.g. funding health promotion, education of health professionals) were defined well as examples of how fostering conditions can look like.

Findings indicate that developing incentive systems (e.g. financing rules) for health-oriented practices (health promotion and health literacy measures) in/by primary care units are key for broad implementation of health-oriented primary care, but still not yet in place.

\section{Meso-level}

In the first step, the project developed an ideal organizational model for a health-promoting and health literate primary care unit (Rojatz et al., 2018) to provide a basic definition of salutogenic primary care. This seemed necessary as previous studies showed that health professionals in Austria only have a vague conceptual understanding of health as a comprehensive concept and its applications in practice. They mostly understand health promotion just as prevention, particularly as vaccination (Rumpelsberger, 2012; Schein, 2012). In discussions with primary care staff also the understanding of health literacy and health literate organizations was found to be limited. Therefore, the organizational model draws on key elements of health-promoting primary care based on Watson (2008) and health-promoting hospitals and health services (Pelikan et al., 2005) as well as health literate primary care organizations (Dietscher \& Pelikan, 2016; ÖPGK, 2019). The model considers the health of all people involved (i.e. patients, staff and community) and the need to integrate the tasks of primary care, local social services, and community activities.
In a second step, the manageability of planning a healthoriented primary care unit was supported by developing a guideline ('blueprint') for the care concept that the founders of a primary care unit have to produce to be funded. This guideline indicates where disease prevention, health promotion, and health literacy have to be considered when systematically planning and implementing these aspects in primary care units (Sprenger et al., 2018).

\section{Micro-level}

Besides basic concepts for orientation and planning of a health-oriented primary care unit, competent health professionals are needed who comprehend the basic perspective of salutogenesis and its theoretical underpinning and its practical application in everyday routine. Therefore, a starter toolkit for primary care staff was developed. It provides introductions to the concepts of health, salutogenesis, health promotion, disease prevention, health literacy, and info sheets on selected easy to implement measures (e.g. checklists for health information, preventive check-up). Implementation was started with these 'low hanging fruits' to allow health professionals to be successful and motivated to implement these new tasks further. Particular attention was paid to health literacy as a prerequisite for improving the interaction between patients and health professionals (quality of conversation, patients asking questions and shared decision-making). These communicative measures are specially meant to strengthen the SOC of patients. More sophisticated measures like self-assessing the organizational health literacy shall set the basis for establishing a general health orientation within the primary care unit. The starter toolkit also recommends establishing a coordinating person for health promotion and health literacy in the primary care unit. Especially measures like social prescribing (referring patients for support to social services in the community) call for better coordination of regional health promotion services.

The dissemination of the starter toolkit was supported by (health promotion) experts of the local social insurance funds. The primary care units have started to pilot the starter toolkits, and a first evaluation was conducted in 2020 .

\section{Application of Salutogenesis}

What can and does primary care contribute to our ability to make us swim in the dangerous river of life? (Antonovsky, 1996). In this section, we summarize our observations regarding applying salutogenesis to primary care in policy, research, and practice and try to answer how far it has come. 
Moreover, we try to summarize fostering and hindering factors for the allocation of salutogenesis in primary care.

The application of salutogenesis as an orientation gets tailwind implicitly from the current efforts to strengthen primary care to combat chronic diseases (OECD, 2019) and of WHO by linking public health and primary care (WHO, 2018b). WHO and others work on breaking down the silos between public health and primary care services and strive to integrate public health functions (in specific health promotion and disease prevention) into primary care. This linkage should not only lead to more health orientation but also emphasizes a population-approach.

Primary care has to respond to current health demands that affect broad segments of the population. At present, it is infectious diseases (Covid-19) and chronic diseases in particular that are causing problems. This can promote an orientation towards illness if it is more about regular invitations to preventive medical check-ups, identifying and treating deviations in laboratory values or lifestyle, and in particular, neglecting the relationship aspects - also to the doctor. Authors even describe a recent shift away from the doctorpatient relationship to disease as an organizational principle (Rudebeck, 2019) or the shift from healing to symptom management (Rakel, 2008).

Especially the relationship aspect is important when addressing chronic diseases. Chronic diseases illustrate quite well that the dichotomization of healthy and sick people is insufficient and supports the health-dis-ease continuum concept. People continuously have to manage their life concerning health and disease, in better and worse times, or as Antonovsky (1996) proposed - on varying positions on the health-dis-ease continuum. They must integrate their role as a patient with other roles and aspects of life, which underlines the need to understand (and treat) patients holistically.

An important resource supporting chronically ill patients is the continuous relationship with the associated mutual trust and knowledge of doctor and patient in primary care. This resource is also implicitly expressed in the term family medicine. The definition of general physicians and family medicine indicates that comprehensiveness and relational medicine - essential aspects of salutogenic practice - have been key to primary care for a long time (Institute of Medicine (US) Committee on the Future of Primary Care, 1994).

One's chronic disease can be the reason for ongoing consulting with one's general practitioner. The relationship between doctor and patient builds trust. These specific resources enable a specific response to the needs and possibilities of the help-seeking person. A quality that increases with the time of care or the length of the illness. A salutogenic orientation might counteract this development of medicalization. This reorientation of primary care towards salutogenesis includes a shift from:
- Deficit orientation to resource orientation.

- Reactive to proactive action - also reaching those who do not regularly visit primary care.

- Medical focus to social health determinants (e.g. via social prescribing, GPs can refer patients to link workers who identify with the patient his/her social needs and make respective offers in the region).

- The individual patient to families and local communities.

- 'God in white' to the co-production of health, by the primary care team, with the patients and the local community.

Primary care operates in an area of tension between health and disease orientation. It is up to the actors involved to decide whether they see themselves as more oriented towards disease-oriented general practitioners or resource-oriented family medicine. Of course, the decision is influenced by the given framework conditions.

A salutogenic orientation in health care means considering all persons involved, and therefore, the SOC of patients, primary care staff, and the local community (we recognize that the community SOC concept is problematic since 'community' is not a subject).

SOC was introduced primarily on the individual level, referring to patients and primary care staff. Most studies on salutogenesis and primary care identified in our review refer to single interventions using the SOC either as a measure to assess the preliminary SOC of people in a population (as indictor for planning subsequent measures) or an outcome measure for evaluating interventions.

Only limited research was identified referring to the SOC of primary care staff (Ejlertsson et al., 2018; Mazur et al., 2018; Palsson et al., 1994; Siber et al., 2009). Heavy workload by a shortage of staff and competing priorities (acute care seems more important) leads to a lack of time for health promotion. This indicates the need to develop salutogenic conditions on the meso- and macro-levels for primary care.

No study was identified to SOC on the community level as SOC refers to subjects. However, one can assume that primary care can influence a community's ability to cope with health problems. This is especially relevant because large proportions of the general population have limited health literacy (Sørensen et al., 2015) and thereby have only a limited understanding of their health situation and might remain in an unhealthy lifestyle. A weak SOC of (potential) patients especially indicates the need for actions and specific measures to respond to their health needs.

Besides individual health needs, there are also ones on the community or population level. As the complexity of treatment options and health information grows, improving the community's health literacy is ever more critical.

Table 38.1 outlines the SOC concept in terms of comprehensibility, manageability, and meaningfulness dimensions. 


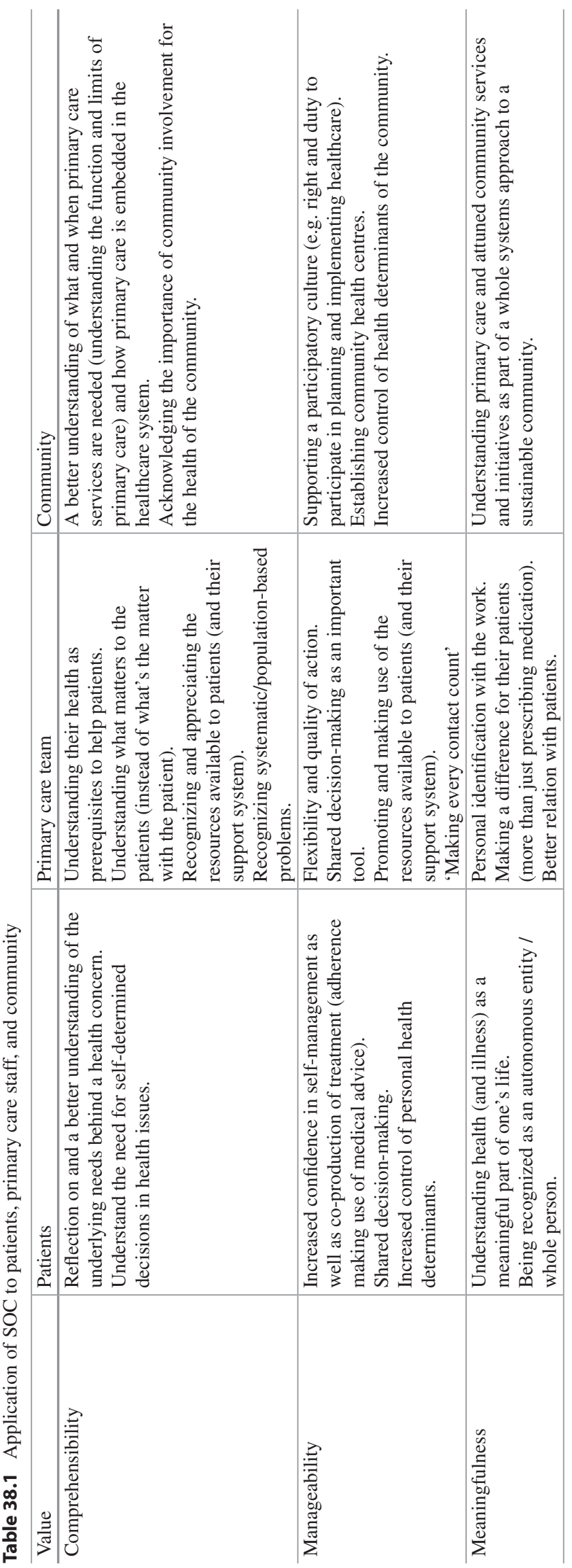


Also, the cooperation of health care, social services, selforganized activities, or integrated health services supports the development of SOC on a health system level. This is indicated by the WHO term of 'primary health care' and its efforts to better link primary care and public health (WHO, 2018a).

A sound theoretical and practical model can support the development of 'salutogenic primary care'. Health promotion measures in practice are often rather an add-on to primary care services than an integral part of primary care's core processes based on an explicit salutogenic model (Peckham et al., 2017). There is scarce published research on the application of salutogenesis as a model for primary care settings. It was used for single interventions in primary care like review dialogue and a health-oriented language (Hollnagel et al., 2000; Malterud \& Hollnagel, 1997, 1998). These interventions aim to change the core unit of production - the interaction between patients and health professionals (Hart, 1998), but not the organizational principles of primary care. We have only identified one model concerning salutogenic health care. Jonas et al. (2014) propose four domains of healing and healing-oriented practice and environments (HOPE):

- Inner environment (personal wholeness, autonomy).

- Interpersonal environment (the relationship between patients, staff, and community).

- Behavioural domain.

- External environment (PHC).

Other models like that of health literate (primary) care organizations also aim in this direction (Dietscher \& Pelikan, 2016; ÖPGK, 2019). Although salutogenesis is not explicitly mentioned therein, health literacy's basic concept can be related to that of the SOC (Dietscher et al., 2017). Therefore, the implementation of standards for health literate primary care organizations could be seen as a first application of the SOC concept.

Based on the considerations made in this chapter, we can also make initial derivations of a SOC model in primary care. The mode of implementation or manageability is relationship work and participation - relationship works with the patient (and his/her family and professional environment), with the health and social system and initiatives in the local population. The significance arises from the fact that humans, as social beings, to be healthy, must be in resonance with themselves, their environment, and the world.

In practice, compliance and adherence are big issues. For a person who is about to be evicted, averting this may be the more prioritized health need than the medical need to reduce too high blood sugar level, which does not hurt. This example shows that those seeking help might have good reasons why they do not follow well-intended advice: so-called 'intelligent non-compliance', practical implementation problems in everyday life and other health goals (Scheibler, 2003).
Two developments can be observed in primary care to address the SOC of primary care. On the one hand, the spread of social prescribing measures shows that non-medical needs are also health-relevant and need to be addressed. On the other hand, the hype about health literacy shows that medical care also requires an orientation towards patients' possibilities in addition to evidence-based information. Information that is not understandable, assessable and implementable for patients is of little help.

With its holistic approach and good relationship, primary care is in a good position to identify and address patients' medical and non-medical health needs. This underlines the importance of a good therapeutic relationship for the successful co-production of jointly shared health goals. Good communication and person-centredness seem key to cope with medical and non-medical health needs. Here a salutogenic orientation can be the guiding principle in understanding and designing beneficial relationships. Approaches like the Review Dialog for the interaction between patients and health professionals or social prescribing for linking patients with social support (Woodall et al., 2018) seem to be appropriate measures to strengthen individuals' SOC.

In sum, there are only a few examples known that use some kind of salutogenic model for the application in primary care. These initiatives need feedback systems (e.g. evaluation by researchers) to make progress visible (Bahrs et al., 2015; Bahrs et al., 2017; Malterud \& Hollnagel, 1998; Matthiessen, 2010) and exemplify what is 'attainable' (Fischer, 2012). Such feedback also promotes the SOC of the involved actors and the ability to be empowering to their patients (Meier Magistretti et al., 2019).

\section{Lessons for Implementation}

The successful implementation of a health-oriented, comprehensible, meaningful and manageable primary care is a complex and long-lasting process including multi-strategic interventions on the macro-level of public discourse and health policy, measures on the organizational level (meso), and skills training for health professionals as well as empowering patients by respective interaction (micro). Building on our two case studies and the literature review, we summarize the facilitating factors (=resources) for the implementation of salutogenesis in primary care.

Public campaigns can promote general awareness of the importance of health promotion among primary care patients and the general population (Rubio-Valera et al., 2014). Because positive attitudes and behaviours towards the health promotion of patients, practice managers, and colleagues affect the implementation (Rubio-Valera et al., 2014).

Education of health professionals in health promotion and salutogenesis is important in two ways: Building on existing resources and knowledge provides essential skills and forms 
the self-concept, attitudes, and the understanding of the professional roles of prospective health professionals (RubioValera et al., 2014). Furthermore, it supports developing a shared vision and mission of health-promoting (salutogenic) primary care (De Maeseneer et al., 2008; van den Muijsenbergh \& van Weel, 2019). The (professional) helpers have to foster their 'sense FOR coherence' (Meier Magistretti et al., 2019). Specific communicative skills, including health literacy skills, are central for person-/people centred care. In addition to health professionals' basic education, primary care facilities can initiate such initiate-specific training for their staff locally.

Primary care staff can also be supported for salutogenic primary care by quality circles and establishing or using existing networks to exchange experiences and provide mutual support.

The many and varied salutogenic primary care tasks require differentiated professional skills in specific roles and processes within the primary care organization that usually can only be realized in multi-professional teams.

Defining one person responsible for coordinating health promotion ('health-promotion coordinator') in the primary care facility gives the topic a 'face' and increases the facility's implementation. There is still a lack of clarity on which professionals in primary care are responsible for carrying out these activities (Boyce et al., 2010).

Models of good practice, guidelines, and tools can support practical implementation. Results and experiences from the Health-Promoting Hospitals and Health Services Network and Health Literate Health Care Organizations can be used as models of good practice (Dietscher \& Pelikan, 2016). Guidelines and tools and easy-to-use handouts for patients can support immediate practice (RubioValera et al., 2014; Sammut, 2006). But the local participatory adaptation of these tools to the specific organizational context is essential. Practical tools need to be accompanied by a process of developing the basic vision, understanding, and attitudes of holistic health, well-being, and realizing salutogenesis.

Recommending health-promoting measures in the local context requires knowledge of these measures and good accessibility for patients, especially those with low socioeconomic status (Rubio-Valera et al., 2014). Establishing regional managers or the links to regional measures (e.g. health city networks) can support regional offers by the primary care facility. In particular, social prescribing can be implemented as a systematic approach (Polley et al., 2017; Woodall et al., 2018). These broader local processes also support the development of a salutogenic orientation and practice in the local community.

Incentives and funding for health promotion provide extrinsic motivation. Primary care managers can be motivated by reimbursement of health promotion measures. Policymakers and health authorities have to emphasize inte- grating health promotion into primary care in legislation, care planning, and reimbursement rules (Rubio-Valera et al., 2014; van den Muijsenbergh \& van Weel, 2019).

Research is still needed to provide supportive evidence on the (cost-)effectiveness of health promotion measures. Evidence on the effectiveness of health promotion and a good knowledge transfer to health professionals can support the attitude and behaviour of health professionals (Rakel, 2008; Rubio-Valera et al., 2014) and the confidence of patients in the effectiveness of these activities (Boyce et al., 2010).

Collaboration (co-production) between all actors in primary care is essential. This includes patients and health professionals, researchers, and decision-makers on all relevant administrative levels. Emphasizing staff and users' participation as a necessary element of salutogenic primary care will help restore relationship-based medicine (Rudebeck, 2019). Also, the integration of primary care with local public health enhances the possibilities of effective salutogenic interventions (WHO, 2018b).

\section{Conclusions}

Primary care as the first level of care is close to the 'dangerous river of life' of people. Through their continuous relationship with patients and communities, primary care staff is excellent in supporting people's ability to swim. They can identify and support general resistance resources that are not recognized in the more specialized and technologized healthcare sectors. Primary care staff has (implicit) knowledge on community-based health determinants and knowledge regarding problems when guiding patients' navigation through the healthcare system. Thus, salutogenic primary supports a deeper understanding of risks, stressors, resources, and SOC within the salutogenic model.

In practice, primary care is under pressure. People meet with healthcare professionals under conditions of heavy strain, and the number of health professionals in primary care still decreases. Unmet needs and problematic conditions (long waiting times, little time to talk and dense workload) accompanied by steering and financing problems indicate the urgency for action. This is recognized and taken up by supra-organizations (OECD, WHO). For improving the situation, primary care also can be an entry point for salutogenic reorientation in health services. 'A whole-of-society approach' has to take into account salutogenic patient-health professional interaction (micro), and reorientation on the organizational level (meso) as well as the development of the systems level (macro). This includes promoting integrated care and collaboration by the social and medical sectors and civic society (e.g. self-help groups). In this way, the broader determinants of health and the comprehensive and interrelated aspects of physical, mental, and social health and com- 
munities' well-being can be addressed (WHO and UNICEF, 2018)

Supranational organizations, like the WHO, recognize the need for action, and many states have adopted the AstanaDeclaration (WHO, 2018a). Moreover, we can see some need for research from what has been said so far. Research can demonstrate the meaningfulness and manageability of the salutogenic primary care concept.

Concerning the application of salutogenesis as a model in primary care, we could only give a rough sketch here. The continuation of our approach of borrowing from existing concepts for health-promoting hospitals and health literate primary care units could be fruitful to develop a model of a salutogenic primary care unit. The research could also identify where and how the salutogenesis model is used at different levels in different countries.

Concerning the use of salutogenesis as a SOC in primary care, it could be possible to use cases of positive deviation as a basis for a targeted investigation of where and why groups of people with insufficient health opportunities benefited from interventions, contrary to the 'inverse care law' (Hart, 1971). We see a great need for research on the relationship between salutogenic resources (and the possibility of promoting them) among healthcare providers and their patients.

Research on salutogenesis in everyday primary care needs to consider the complexity of the interventions and the context. This calls for participatory research methodologies with a salutogenic perspective, which can contribute to the comprehensibility, meaningfulness, and manageability of people's health and the 'health' of the healthcare organizations and policy (International Network of Health Promoting Hospitals and Health Services et al., 2016).

Concluding, our theoretical and empirical analysis underlines that salutogenic primary care is a promising and feasible approach to sustainable primary care. The salutogenic approach supports person-centred care, universal health coverage, and the population's health and well-being. The broad establishment of salutogenic primary care requires a commitment to participatory methods in practice, policy, and research.

\section{References}

Acheson, D. (1988). Public health in England: The report of the committee of inquiry into the future development to the public health function. The Stationery Office.

Antonovsky, A. (1996). The salutogenic model as a theory to guide health promotion. Health Promotion International, 11, 11-18.

Antonovsky, A. (1979). Health, stress and coping. Jossey-Bass.

Arvidsdotter, T., Marklund, B., Taft, C., \& Kylén, S. (2015). Quality of life, sense of coherence and experiences with three different treatments in patients with psychological distress in primary care: A mixed-methods study. BMC Complementary and Alternative Medicine, 15, 132. https://doi.org/10.1186/s12906-015-0654-z
Bahrs, O. (2011). Der Bilanzierungsdialog - Eine Chance zur Förderung von Ressourcenorientierung in der Langzeitversorgung von Patienten mit chronischen Krankheiten. Great Green Wall, 11, $7-15$.

Bahrs, O., \&Andres, E. (2016). Qualitätszirkel-Professionsentwicklung im Gesundheitswesen. In M. Dick, W. Marotzki, \& H. Mieg (Eds.), Handbuch Professionsentwicklung (pp. 295-309). Klinkhardt.

Bahrs, O., Heim, S., Kalitzkus, V., et al. (2004). Salutogenesis in general practice. How to use the potential of doctor-patient-communication to promote health. In P. Twohig \& V. Kalitzkus (Eds.), Making sense of: Health, illness and disease II (pp. 149-161). Rodopi.

Bahrs, O., Heim, S., Löwenstein, F., \& Henze, K. (2017). Review dialogues as an opportunity to develop life course specific health goals. International Journal of Person Centered Medicine, 7, 98-106.

Bahrs, O., \& Henze, K. (2019). From shame to pride - Initiation of processes of de-stigmatisation in review dialogues. In: C. Mayer, \& E. Vanderheiden (Eds.), Transforming shame in culture and context: Practical applications and exercises for growth (pp 363-378). Springer Nature Switzerland. Switzerland.

Bahrs, O., Henze, K., Löwenstein, F., et al. (2015). Review dialogues as an opportunity to develop a person-related overall diagnosis. International Journal of Personalized Medicine, 5, 112-119.

Bahrs, O., \& Matthiessen, P. (Eds.). (2007). Gesundheitsfördernde Praxen - Die Chancen einer salutogenetischen Orientierung in der hausärztlichen Praxis. Hans Huber.

Batalden, M., Batalden, P., Margolis, P., et al. (2016). Coproduction of healthcare service. BMJ Quality and Safety, 25, 509-517. https:// doi.org/10.1136/bmjqs-2015-004315

Bauer, G. F., Roy, M., Bakibinga, P., et al. (2019). Future directions for the concept of salutogenesis: A position article. Health Promotion International, 1-9. https://doi.org/10.1093/heapro/daz057

Bergh, H., Baigi, A., Fridlund, B., \& Marklund, B. (2006). Life events, social support and sense of coherence among frequent attenders in primary health care. Public Health, 120, 229-236. https://doi. org/10.1016/j.puhe.2005.08.020

Bhuyan, K. (2004). Health promotion through self-care and community participation: Elements of a proposed programme in the developing countries. BMC Public Health, 4, 11. https://doi. org/10.1186/1471-2458-4-11

Blättner, B., \& W aller, H. (2011). Gesundheitswissenschaft - Eine Einführung in Grundlagen, Theorie und Anwendung. Kohlhammer.

BMGF. (2018). ÖSG 2017. Österreichischer Strukturplan Gesundheit 2017. BMGF. Wien.

Boyce, T., Peckham, S., \& Hann, A. (2010). A pro-active approach. Health Promotion and Ill-health prevention Health Promotion and Ill-health prevention. The King' s Fund.

Braun, V. (2004). Salutogenetic aspects in general practice I Salutogene inhalte hausärztlichen seins. Zeitschrift für Allgemeinmedizin, 80, 187-189.

Bundesministerium für Gesundheit. (2014). "Das Team rund um den Hausarzt": Konzept zur multiprofessionellen und interdisziplinären Primärversorgung in Österreich. BMG. Wien.

Dahlgren, G., \& Whitehead, M. (2007). Policies and strategies to promote social equity in health. Institute for Future Studies. Stockholm.

Dalton, C., \& McCartney, K. (2011). Salutogenesis: A new paradigm for pervasive computing in healthcare environments? In: Conference: 5th international conference on pervasive computing technologies for healthcare, PervasiveHealth. Dublin.

De Maeseneer, J., van Weel, C., Daeren, L., et al. (2008). From "patient" to "person" to "people": The need for integrated people-centered healthcare. International Journal of Person Centered Medicine, 2, 601-614.

DEGAM-Praxisempfehlung. (2016). Hausärztliche Versorgung von Patientinnen und Patienten mit Angss. Berlin Retrieved from https://www.degam.de/files/Inhalte/Leitlinien-Inhalte/Dokumente/ DEGAM-Praxisempfehlungen/Hausaerztliche\%20Versorgung $\% 20$ 
von $\% 20$ Patientinnen $\% 20$ und $\% 20$ Patienten $\% 20$ mit $\% 20$ Angst/ DEGAM-PE_Hausaerztliche\%20Versorgung \%20von\% 20 Patientinnen\%20und\%20Patienten\%20mit\%20Angst_27-10-2017. pdf.

DEGAM. (2012). DEGAM-position paper on the future "general practice - Focused on the whole person". Berlin Retrieved from https://www.degam.de/files/Inhalte/Degam-Inhalte/Ueber_uns/ Positionspapiere/DEGAM-Position_Paper_on_the_Future.pdf.

DEGAM. (2017). DEGAM Praxisempfehlung: Das anamnestische Erstgespräch. Berlin Retrieved from https://www.degam. de/files/Inhalte/Leitlinien-Inhalte/Dokumente/DEGAMPraxisempfehlungen/Das\%20anamnestische\%20Erstgespraech/ DEGAM\%20Praxisempfehlung \% 20das \% 20 anam. $\% 20$ Erstgespraech_1-2-2018.pdf.

Dietscher, C., \& Pelikan, J. (2016). Gesundheitskompetente Krankenbehandlungsorganisationen. Prävention und Gesundheitsförderung, 11, 53-62. https://doi.org/10.1007/ s11553-015-0523-0

Dietscher, C., Winter, U., \& Pelikan, J. M. (2017). The application of Salutogenesis in hospitals. In M. B. Mittelmark, S. Sagy, M. Eriksson, et al. (Eds.), The handbook of Salutogenesis (pp. 277298). Springer.

Ejlertsson, L., Heijbel, B., Ejlertsson, G., \& Andersson, I. (2018). Recovery, work-life balance and work experiences important to self-rated health: A questionnaire study on salutogenic work factors among Swedish primary health care employees. Work, 59, 155-163. https://doi.org/10.3233/WOR-172659

Elwyn, G., Frosch, D., Thomson, R., et al. (2012). Shared decision making: A model for clinical practice. Journal of General Internal Medicine, 27, 1361-1367. https://doi.org/10.1007/ s11606-012-2077-6

Erikson, M. (2017). The sense of coherence in the Salutogenic model of health. In M. B. Mittelmark, S. Sagy, M. Eriksson, et al. (Eds.), The handbook of Salutogenesis (pp. 91-96). Springer

Fischer, W. (2012). Chronizität - Was ist wirklich möglich? Der Mensch - Zeitschrift für Salut und Anthropol Medizin, 45, 9-14.

Grant, J., Lines, L., Darbyshire, P., \& Parry, Y. (2017). How do nurse practitioners work in primary health care settings? A scoping review. International Journal of Nursing Studies, 75, 51-57. https:// doi.org/10.1016/j.ijnurstu.2017.06.011

Harnett, P. J. (2018). Improvement attributes in healthcare: Implications for integrated care. International Journal of Health Care Quality Assurance, 31, 214-227. https://doi.org/10.1108/ IJHCQA-07-2016-0097

Hart, J. T. (1998). Expectations of health care: Promoted, managed or shared? Health Expectations, 1, 3-13. https://doi. org/10.1046/j.1369-6513.1998.00001.x

Hart, J. T. (1971). The inverse care law. Lancet, 284, 405-412.

Heggdal, K., \& Lovaas, B. J. (2018). Health promotion in specialist and community care: How a broadly applicable health promotion intervention influences patient's sense of coherence. Scandinavian Journal of Caring Sciences, 32, 690-697. https://doi.org/10.1111/ scs. 12498

Hjalmers, K., Söderfeldt, B., \& Axtelius, B. (2004). Healthy work for female unpromoted general practice dentists. Acta Odontologica Scandinavica, 62, 107-110.

Hollnagel, H., \& Malterud, K. (1995). Shifting attention from objective risk factors to patients' self-assessed health resources: A clinical model for general practice. Family Practice, 12, 423-429.

Hollnagel, H., Malteruda, K., \& Witt, K. (2000). Men's self-assessed personal health resources: Approaching patients' strong points in general practice. Family Practice, 17, 529-534.

Institute of Medicine (US) Committee on the Future of Primary Care (1994). Defining primary care: An interim report. National Academies Press. Washington, D.C.

International Network of Health Promoting Hospitals and Health Services, Plentree, GÖG GmbH. (2016). The New Haven recom- mendations on partnering with patients, families and citizens to enhance performance and quality in health promoting hospitals and health services. Download under: https://www.hphnet.org/wpcontent/uploads/2021/07/New-Haven-Recommendations-TF.pdf

Jamoulle, M., Resnick, M., Van der Stichele, R., et al. (2017). Analysis of definitions of general primary care in the Calais jungle practice, family and primary health care: A terminological analysis. British Journal of General Practice, 1-8. https://doi.org/10.3399/DOI

Jensen, B. B., Dür, W., \& Buijs, G. (2017). The application of Salutogenesis in schools. In M. B. Mittelmark, S. Sagy, M. Eriksson, et al. (Eds.), The handbook of salutogenesis (pp. 225-235). Springer.

Jonas, W. B., States, U., Chez, R. A., et al. (2014). Salutogenesis: The defining concept for a new healthcare system. Global Advances in Health and Medicine, 3, 82-91. https://doi.org/10.7453/ gahmj.2014.005

Kaschel, A. (2018). Sind Bilanzierungsdialoge eine Chance zur Förderung von Patientenzentrierung in der Langzeitversorgung von Patienten mit chronischen Krankheiten? Vergleichende qualitative und quantitative Analyse videodokumentierter Konsultationen. Medizinische Universität Göttingen.

Klein, C., Pertl, D., Rojatz, D., \& Nowak, P. (2017). Gesundheitsförderung im Setting Hausarztpraxis. Gesundheit Österreich GmbH.

Kreher, S., Brockmann, S., Sielk, M., et al. (2008). Hausärztliche Krankheitskonzepte. Analyse ärztlicher Vorstellungen zu Kopfschmerzen, akutem Husten, Ulcus crusis und Schizophrenie. Huber.

Kringos, D., Boerma, W. G. W., Hutchinson, A., \& Saltman, R. B., (Eds). (2015). Building primary care in a changing Europe edited by. European Observatory on Health Systems and Policies, WHO, Denmark.

Kröger, F., \& Altmeyer, S. (2013). Systemic family medicine - A critical review. Familiendynamik, 38, 108-118.

Lagerin, A., Törnkvist, L., \& Hylander, I. (2016). District nurses' experiences of preventive home visits to 75-year-olds in Stockholm: A qualitative study. Primary Health Care Research \& Development, 17, 464-478. https://doi.org/10.1017/S1463423615000560

Malterud, K., \& Hollnagel, H. (1997). Women's self-assessed personal health resources. Scandinavian Journal of Primary Health Care, 15, 163-168. https://doi.org/10.3109/02813439709035021

Malterud, K., \& Hollnagel, H. (1998). Talking with women about personal health resources in general practice : Key questions about salutogenesis. Scandinavian Journal of Primary Health Care, 66, 66-71. https://doi.org/10.1080/028134398750003188

Matthiessen, P. (2010). Paradigmenpluralität, Salutogenese und ärztliche Praxis. Der Mensch - Zeitschrift für Salut und Anthropol Medizin, 10, 6-21.

Mazur, A., Czarkowska, M., Goś, A., \& Humeniuk, E. (2018). Existential attitudes as predictors of burnout in polish nurses employed in rural primary healthcare settings. Annals of Agricultural and Environmental Medicine, 25, 552-558. https://doi.org/10.26444/ aaem $/ 85650$

Meier Magistretti, C., Topalidou, A., \& Meinecke, F. (2019). Sense FOR Coherence - der Sinn FÜR Kohärenz: Annäherungen an ein mögliches Konzept. In C. Meier Magistretti (Ed.), Salutogenese kennen und verstehen (pp. 119-135). Hogrefe.

Muldoon, L., Hogg, W., \& Levitt, M. (2006). Primary care (PC) and primary health care (PHC). What is the difference? Canadian Journal of Public Health, 97, 409-411. https://doi.org/10.1007/BF03405354

OECD. (2019). Realising the full potential of primary health care. https://www.oecd.org/health/health-systems/OECD-Policy-BriefPrimary-Health-Care-May-2019.pdf.

ÖPGK. (2019). Selbsteinschätzungsinstrument für Gesundheitskompetenz in Primärversorgungseinheiten. ÖPGK. Wien.

Palsson, M.-B. E., Hallberg, I. R., Norberg, A., \& Isovaara, S. (1994). Systematic clinical supervision and its effects for nurses handling demanding care situations: Interviews with Swedish district nurses and hospital nurses in cancer care. Cancer Nursing, 17, 385-394. 
Pandey, K. (2018). From health for all to universal health coverage: Alma Ata is still relevant. Globalization and Health, 14, 62. https:// doi.org/10.1186/s12992-018-0381-6

Parker, R. (2009). Measures of health literacy. Workshop summary: What? So what? Now what? http://www.nap.edu/"'hs, Washington.

Peckham, S., Hann, A., Kendall, S., \& Gillam, S. (2017). Health promotion and disease prevention in general practice and primary care: A scoping study. Primary Health Care Research \& Development, $18,529-540$

Pelikan, J. M. (2017). The application of salutogenesis in healthcare settings. In M. B. Mittelmark, S. Sagy, M. Eriksson, et al. (Eds.), The handbook of salutogenesis (pp. 261-266). Springer.

Pelikan, J. M., Dietscher, C., Krajic, K., \& Nowak, P. (2005). 18 Core strategies for health promoting hospitals (HPH). In O. Groene \& M. Garcia-Barbero (Eds.), Health promotion in hospitals: Evidence and quality management (pp. 46-63). World Health Organization.

Pettigrew, L., De Maeseneer, J., Inez, M., et al. (2015). Primary health care and the sustainable development goals. Lancet, 6736, 10-13. https://doi.org/10.1016/S0140-6736(15)00949-6

Polley, M., Fleming, J., Anfilogoff, T., et al. (2017). Making sense of social prescribing. London University of Westminster.

Rakel, D. (2008). The salutogenesis-oriented session: Creating space and time for healing in primary care. Explore, 4, 42-47. https://doi. org/10.1016/j.explore.2007.10.016

Rennemark, M., Holst, G., Fagerstrom, C., \& Halling, A. (2009). Factors related to frequent usage of the primary healthcare services in old age: Findings from the Swedish National Study on aging and care. Health and Social Care in the Community, 17, 304-311. https://doi.org/10.1111/j.1365-2524.2008.00829.x

Rojatz, D., Nowak, P., Rath, S., \& Atzler, B. (2018). Primärversorgung neu: Krankheitsprävention, Gesundheitsförderung und Gesundheitskompetenz. Grundlagen und Eckpunkte eines Idealmodells für PVE-Team und Finanzierungspartner. Gesundheit Österreich GmbH. Wien.

Rosa, H. (2016). Resonanz: Eine Soziologie der Weltbeziehung. Suhrkamp Verlag.

Rubio-Valera, M., Pons-Vigués, M., Martínez-Andrés, M., et al. (2014). Barriers and facilitators for the implementation of primary prevention and health promotion activities in primary care: A synthesis through meta-ethnography. PLoS One, 9, e89554. https://doi. org/10.1371/journal.pone.0089554

Rudebeck, C. E. (2019). Relationship based care-how general practice developed and why it is undermined within contemporary healthcare systems. Scandinavian Journal of Primary Health Care, 37, 335-344. https://doi.org/10.1080/02813432.2019.1639909

Rumpelsberger, K. (2012). Gesund ist, wer nicht krank ist? Subjektive Gesundheitsvorstellungen oberösterreichischer Hausärzte und ihre gegenwärtige und zukünftige. Universität Bielefeld.

Sammut, M. R. (2006). Family doctors and health promotion: Do we practise what we preach? Malta Medical Journal, 18, 26-31.

Sangster-Gormley, E., Frisch, N., \& Schreiber, R. (2013). Articulating new outcomes of nurse practitioner practice. Journal of the
American Association of Nurse Practitioners, 25, 653-658. https:// doi.org/10.1002/2327-6924.12040

Scheibler, F. (2003). Shared Decksion-making: Von der compliance zur partnerschaftlichen Entschei-dungsfindung. Hans Huber.

Schein, S. (2012). Was verstehen niedergelassene Allgemeinmediziner unter "Gesundheitsförderung"? Medizinische Universität Graz.

Siber, G., Endler, P. C., Mesenholl, E., et al. (2009). The sense of coherence among general practitioners|Kohärenzempfinden (Sense of Coherence) bei niedergelassenen Ärztinnen und Ärzten für Allgemeinmedizin. Wiener Medizinische Wochenschrift, 159, 192195. https://doi.org/10.1007/s10354-009-0670-z

Sørensen, K., Pelikan, J. M., Röthlin, F., et al. (2015). Health literacy in Europe: Comparative results of the European health literacy survey (HLS-EU). European Journal of Public Health, 25, 1053-1058. https://doi.org/10.1093/eurpub/ckv043

Sprenger, M. (2012). Resonanz der Versorgungsbereiche. Das österreichische Gesundheitswesen. ÖKZ, 53, 17-20.

Sprenger, M., Stigler, F., Rojatz, D., \& Nowak, P. (2018). Krankheitsprävention, Gesundheitsförderung, Gesundheitskompetenz in der Primärversorgung. Ausfüllhilfe für PVE-Gründer/innen zum Musterversorgungskonzept. Gesundheit Österreich GmbH. Wien.

Starfield, B., Shi, L., \& Macinko, J. (2005). Contribution of primary care to health systems and health. The Milbank Quarterly, 83, 457-502.

Sturm, E., Bahrs, O., Dieckhoff, D., et al. (Eds.). (2006). Hausärztliche Patientenversorgung. Konzepte-Methoden - Fertigkeiten. Thieme. van den Muijsenbergh, M., \& van Weel, C. (2019). The essential role of primary care professionals in achieving health for all. Annals of Family Medicine, 17, 293-295. https://doi.org/10.1370/afm.2436

Watson, M. (2008). Discussion paper going for gold: The health promoting general practice. Quality in Primary Care, 16, 177-185.

WHO. (1978). Declaration of Alma - Ata. International Conference on Primary Health Care, Alma - Ata, USSR, 6-12 September 1978.

WHO. (2018a). Declaration of Astana. Global conference on primary health care. WHO.

WHO. (2018b). Primary health care: Closing the gap between public health and primary care through integration. WHO.

WHO. (2019). Thirteenth general programme of work 2019-2023. Promote Health. Keep the world safe. Serve the vulnerable. WHO.

WHO. (1986). Ottawa charter for health promotion. WHO.

WHO Europe. (2012). European action plan for strengthening public health capacities and services. WHO Regional Office for Europe. Malta.

WHO, UNICEF. (2018). A veision for primary health care in the 21 st century. Geneva.

Woodall, J., Trigwell, J., Bunyan, A.-M., et al. (2018). Understanding the effectiveness and mechanisms of a social prescribing service: A mixed method analysis. BMC Health Services Research, 18, 604.

Open Access This chapter is licensed under the terms of the Creative Commons Attribution 4.0 International License (http://creativecommons. org/licenses/by/4.0/), which permits use, sharing, adaptation, distribution and reproduction in any medium or format, as long as you give appropriate credit to the original author(s) and the source, provide a link to the Creative Commons license and indicate if changes were made.

The images or other third party material in this chapter are included in the chapter's Creative Commons license, unless indicated otherwise in a credit line to the material. If material is not included in the chapter's Creative Commons license and your intended use is not permitted by statutory regulation or exceeds the permitted use, you will need to obtain permission directly from the copyright holder. 